\title{
FLIBE USE IN FUSION REACTORS: AN INITIAL SAFETY ASSESSMENT
}

\author{
L. C. Cadwallader \\ G. R. Longhurst
}

LOCKHEEDMARTIN 


\title{
Flibe Use in Fusion Reactors: An Initial Safety Assessment
}

\author{
Lee C. Cadwallader \\ Glen R. Longhurst
}

Published March 1999

Idaho National Engineering and Environmental Laboratory Idaho Falls, Idaho 83415

Prepared for the

U.S. Department of Energy

Office of Science

Under DOE Idaho Operations Office

Contract DE-AC07-94ID13223 


\begin{abstract}
This report is an initial effort to identify and evaluate safety issues associated with the use of Flibe $\left(\mathrm{LiF}-\mathrm{BeF}_{2}\right)$ as a molten salt coolant for nuclear fusion power plant applications. Flibe experience in the Molten Salt Reactor Experiment is briefly reviewed. Safety issues identified include chemical toxicity, radiological issues resulting from neutron activation, and the operational concerns of handling a high temperature coolant. Beryllium compounds and fluorine pose be toxicological concerns. Some controls to protect workers are discussed. Since Flibe has been handled safely in other applications, its hazards appear to be manageable. Some safety issues that require further study are pointed out. Flibe salt interaction with strong magnetic fields should be investigated. Evolution of Flibe constituents and activation products at high temperature (i.e., will Fluorine release as a gas or remain in the molten salt) is an issue. Aerosol and tritium release from a Flibe spill requires study, as does neutronics analysis to characterize radiological doses. Tritium migration from Flibe into the cooling system is also a safety concern. Investigation of these issues will help determine the extent to which Flibe shows promise as a fusion power plant coolant or plasma-facing material.
\end{abstract}




\section{CONTENTS}

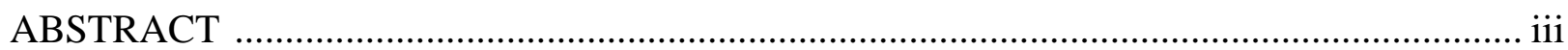

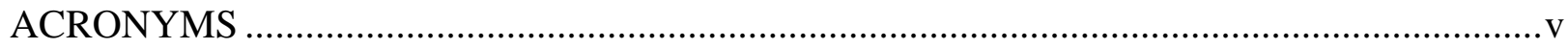

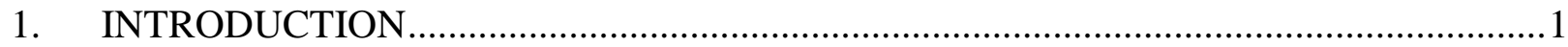

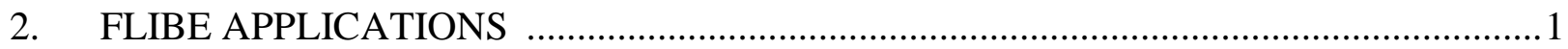

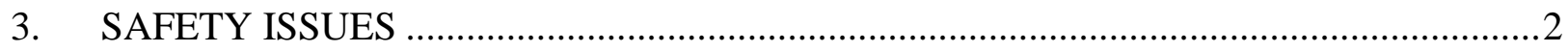

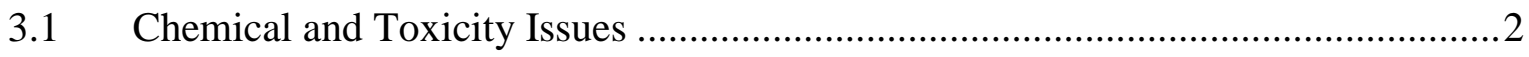

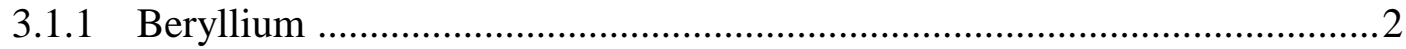

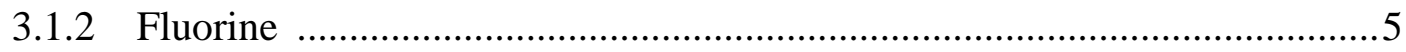

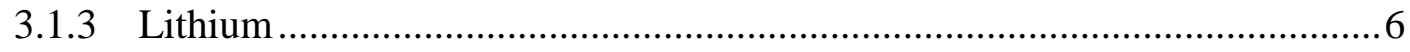

3.2 Activation Concerns ...............................................................................

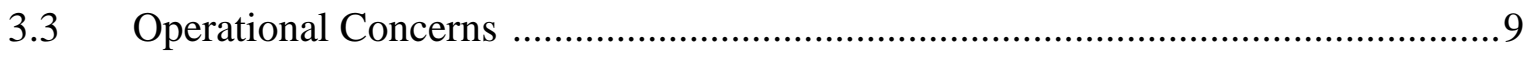

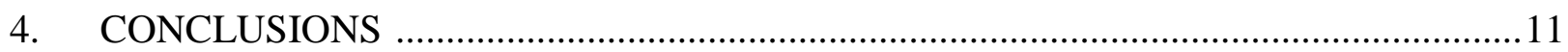

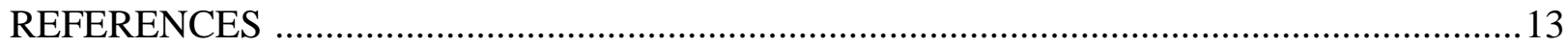

APPENDIX A. Preliminary Personnel Safety Master Logic Diagram ..................................17

\section{TABLES}

1. Threshold Limit Values for unirradiated Flibe constituents and impurities .....................3

\section{FIGURES}

1. Activation and decay paths for lithium and beryllium in Flibe ....................................

2. Activation and decay processes for fluorine in Flibe and oxygen impurity .....................8 


\section{ACRONYMS}

ACGIH American Conference of Governmental Industrial Hygienists

ALPS Advanced Liquid Plasma Surface study

APEX Advanced Power Extraction study

DOE Department of Energy

IDLH Immediately Dangerous to Life or Health

IFE Inertial fusion energy

MFE Magnetic fusion energy

MSRE Molten Salt Reactor Experiment

NIOSH National Institute for Occupational Safety and Health

ORNL Oak Ridge National Laboratory

OSHA Occupational Safety and Health Administration

TLV Threshold limit value 


\section{FLIBE USE IN FUSION REACTORS A SAFETY ASSESSMENT}

\section{INTRODUCTION}

The molten salt mixture of $\mathrm{LiF}$ and $\mathrm{BeF}_{2}$, commonly referred to as Flibe, is under consideration for use in fusion reactors. In magnetic fusion energy (MFE) reactor designs, the Flibe has been considered as a renewable surface for interfacing with the plasma in high plasma-flux regions and as a tritium-breeding coolant. In inertial fusion energy (IFE) designs, it has been considered as a shielding medium from both neutrons and the hydrodynamic blast of IFE targets. In this report, we consider safety issues associated with such uses. These include chemical and radiological concerns with regard to biological effects as well as those associated with its operational and environmental hazards. Except as relevant to particular safety aspects being discussed here, no effort will be made to catalogue the various mechanical and chemical properties of Flibe, since those have been provided elsewhere.[1-14]

\section{FLIBE APPLICATIONS}

The use of molten Flibe as a coolant for a magnetic fusion reactor has several engineering advantages. Flibe serves as a high temperature heat transfer fluid that achieves high thermal efficiencies, acts as a good radiation shield, and has modest to good fluid flow properties.[15]

Flibe is used at high temperature, but low pressure. Any ex-vessel cracks in the coolant piping are expected to produce small leaks, due to the low coolant pressure. Only a low frequency pipe rupture event (i.e., less than $10^{-4}$ year) should lead to a large coolant spill.

The first major use of Flibe for nuclear power applications was in the $8 \mathrm{MW}_{\text {th }}$ Molten Salt Reactor Experiment (MSRE) constructed at Oak Ridge National Laboratory (ORNL).[16] Operating between June 1965 and May 1969, the MSRE used a mixture of 66 mole\% LiF and 34 mole\% $\mathrm{BeF}_{2}$ at 545 to $580^{\circ} \mathrm{C}, 34.4 \mathrm{kPa}$ gauge pressure, and $54 \mathrm{~L} / \mathrm{s}$ circulation rate as an intermediate coolant.

One of the early applications of Flibe in fusion reactor designs was in HYLIFE-II.[17] In that design, Flibe was circulated at the rate of about $60 \mathrm{~m}^{3} / \mathrm{s}$ through a set of fixed and oscillating jets and served to shield the first wall from the blast and neutrons as well as to breed tritium. The two banks of movable jets, oscillating sinusoidally but $180^{\circ}$ out of phase with each other, provided a moving cavity into which a target pellet could be fired (as from a rifle) and ignited by either laser or heavy ion beam drivers. The stationary jets completed the coverage for the shielding function.

Since then, Flibe has been considered as a coolant and as a plasma-facing material by the Advanced Liquid Plasma Surface (ALPS) and Advanced Power Extraction (APEX) projects within the US DOE Office of Fusion Energy Sciences. Studies are presently underway to develop methods of getting molten Flibe to conform to the desired shapes in dynamic flow 
situations and to investigate tritium breeding and extraction, chemical compatibility, and other issues relevant to the application of Flibe in advanced magnetic fusion designs.[18-20]

\section{SAFETY ISSUES}

In this report we consider various safety aspects connected with the use of Flibe. Those are in three major categories. The first relates to the chemical and toxicity hazards of the material itself. The second is the risk to health posed by activation and radioactivity. The third is a more general look at safety concerns associated with industrial hazards and the use of Flibe in typical fusion reactor systems.

\subsection{Chemical and Toxicity Issues}

Fortunately, the Flibe itself is not a combustible material. The magnetic field [21] effects will have to be evaluated to see if Flibe dissociation occurs, and if so, will yield any appreciable amounts of constituent elements that are flammable. Radiolysis is known to cause dissociation, but the evolution of flammable compounds remains to be evaluated for the fusion environment. Moir [15] states that Flibe recombines reasonably fast from radiolytic decomposition, and it is also expected to quickly recombine from the Hall effect as well because of the chemically reactive nature of fluorine.

Individually, the chemical constituents of Flibe, fluorine, lithium, and beryllium, are highly reactive and therefore hazardous materials. When reacted together to form $\mathrm{LiF}$ and $\mathrm{BeF}_{2}$, however, they become rather passive and do not show substantial chemical reactivity.

Beryllium is tentatively labeled a carcinogen [22-24], and exposure may lead to deleterious lung function. Lithium fluoride has not yet been investigated by the scientific community for its toxicity. There could be exposure to corrosion products as well.

Two of the constituents of Flibe (beryllium and fluorine) and several of its impurities have threshold limit values (TLVs) for airborne exposure [25]. The current TLVs are given in Table 1. While the Flibe salt will have only the beryllium compound TLV, that TLV is a low value. The low TLV indicates that even small releases will pose a health threat. However, it is also important to point out that all these substances are present in the ambient environment in many locations. The average crustal value of beryllium concentration in the earth's surface has been reported to be $2.8 \mu \mathrm{g} / \mathrm{g}$ [26], and typical concentrations in surface water are 0.01 to $1.0 \mathrm{ng} / \mathrm{g} .[27]$

\subsubsection{Beryllium}

For beryllium, the primary target organ is the lung, with concerns for both acute and chronic exposures. Acute exposure by inhaling beryllium fluoride produces an inflammatory reaction of the entire respiratory tract; in the most severe cases it produces acute fulminating pneumonitis. Though not universally agreed to, the severity appears to be related to dosage, and exposed individuals can recover after weeks or months.[28,29] It is highly selective among individuals, 
Table 1. Threshold limit values for unirradiated Flibe constituents and impurities. ${ }^{a}$

\begin{tabular}{|c|c|c|}
\hline Element or compound & $\begin{array}{c}\text { 8-hour TLV } \\
(\mathrm{mg} / \mathrm{m} 3)\end{array}$ & $\begin{array}{c}\text { IDLH concentration } \\
(\mathrm{mg} / \mathrm{m} 3)\end{array}$ \\
\hline \multicolumn{3}{|l|}{ Beryllium } \\
\hline NIOSH & 0.0005 & 4, carcinogen \\
\hline ACGIH & 0.002, STEL is 0.01 & \\
\hline OSHA & $0.002, \mathrm{C}$ is 0.005 & \\
\hline $\begin{array}{l}\text { OSHA } \\
\text { see note b }\end{array}$ & STEL is 0.025 & \\
\hline \multicolumn{3}{|l|}{ Beryllium compounds } \\
\hline NIOSH & 0.025 & \\
\hline ACGIH & $0.002, \mathrm{STEL}$ is 0.01 & \\
\hline OSHA & same as for Be metal & \\
\hline \multicolumn{3}{|l|}{ Carbon (as graphite) } \\
\hline NIOSH & 2.5 & 1250 \\
\hline ACGIH & 2 & \\
\hline OSHA & 5 (respirable dust, sy & thetic) \\
\hline OSHA & 15 (total dust, synthe & \\
\hline \multicolumn{3}{|l|}{ Cobalt $^{\mathrm{c}}$} \\
\hline NIOSH & 0.1 & 20 \\
\hline ACGIH & 0.02 & \\
\hline OSHA & 0.1 & \\
\hline
\end{tabular}

Fluorine

NIOSH $\quad 0.2 \quad 39$

ACGIH $\quad 1.6$, STEL is 3.1

OSHA $\quad 0.2$

Iron oxide

$\begin{array}{lll} & \text { NIOSH } & 2500\end{array}$

ACGIH 5

OSHA $\quad 10$

Lithium no TLV for LiF was listed ${ }^{\mathrm{d}}$

Manganese compounds ${ }^{\mathrm{c}}$

NIOSH

ACGIH

5 as Ceiling

500

OSHA

0.2

5 as Ceiling 
Table 1. Continued.

\begin{tabular}{|c|c|c|}
\hline Element or compound & $\begin{array}{c}\text { 8-hour TLV } \\
(\mathrm{mg} / \mathrm{m} 3)\end{array}$ & $\begin{array}{c}\text { IDLH concentration } \\
(\mathrm{mg} / \mathrm{m} 3)\end{array}$ \\
\hline Scandium & \multicolumn{2}{|c|}{ no TLV for $\mathrm{Sc}$ was listed } \\
\hline \multicolumn{3}{|l|}{ Zinc oxide $^{c}$} \\
\hline NIOSH & 5 (respirable dust) & \\
\hline NIOSH & 15 (total dust) & 500 \\
\hline ACGIH & not listed & \\
\hline OSHA & 5 (respirable dust) & \\
\hline OSHA & 15 (total dust) & \\
\hline \multicolumn{3}{|l|}{$\begin{array}{l}\text { Particulates not } \\
\text { otherwise regulated }\end{array}$} \\
\hline OSHA & 5 (respirable dust) & \\
\hline OSHA & 15 (total dust) & \\
\hline
\end{tabular}

Note a: Values are from NIOSH [25], ACGIH [30], and OSHA [31]. IDLH stands for Immediately Dangerous to Life or Health; workers must exit the area immediately to reduce exposure to the airborne chemical.

Note b: Beryllium has a proposed DOE rule to reduce the eight hour average worker exposure to an action limit of $0.5 \mu \mathrm{g} / \mathrm{m}^{3}$ of air, see the "Chronic Beryllium Disease Prevention Program," Federal Register, Volume 63, No. 232, December 3, 1998, pages 66940-66975.

Note c: It is assumed that some amount of oxide formation will occur when these impurities at elevated temperature are exposed to air. While masses of impurities should be small, the chemistry of these impurities must be investigated to determine the severity of the safety concern.

Note d: Lithium hydride is the only lithium compound for which an airborne exposure standard has been established. The TLV is $0.025 \mathrm{mg} / \mathrm{m}^{3}$. [25,30,31] $\mathrm{LiF}$ is a soluble lithium compound that would be readily absorbed by ingestion and slowly absorbed through the skin as an ionized salt; lithium distribution in the body appears to be rapid and uniform (it does not appear to seek organs). Lithium salts are diuretic.[32] This can pose a health threat if a person receives a large acute dose. Fluorine at elevated temperature can react with moisture in air to form hydrofluoric acid mist. 
and its incidence appears correlated with levels of beryllium in air at low concentrations but not at high concentrations.[33] Berylliosis or chronic beryllium disease may be localized to the lungs, or systemic involvement may also occur. As beryllium or beryllium compound particles accumulate in the lungs over time, small interstitial granulomas form in the alveoli. In later stages of the disease, the granulomas cause the alveoli to lose functionality, leading to respiratory dysfunction.[28,29] These symptoms may not appear until years after the exposure, and the symptoms can grow worse over time even after cessation of exposure.

Contact dermatitis is another common beryllium toxic effect for occupationally exposed individuals, but there are insufficient data to determine whether it occurs in the general population.[28,23]

$\mathrm{BeCl}_{2}$, being highly soluble in water, poses a greater systemic threat than does free elemental beryllium because of its mobility in the body. Metallic beryllium found in the workplace invariably will be coated with an insoluble oxide film, unless the particle has been freshly cut or abraded. Beryllium fluoride contact may result in lesions on the skin of sensitive individuals as an allergic reaction. If beryllium compounds contact cuts or abrasions in the skin, necrotizing or ulcerative lesions may form, and these may heal very slowly or not heal at all. Surgical excision may be required to heal the wound.[29, 34 ]

Dealing with exposure issues for beryllium and its compounds has been a matter of increasing concern in the U.S. Under the assumption that the number and severity of cases of chronic beryllium disease is related to the level of exposure, the U.S. Department of Energy has recently instituted stricter control measures for monitoring airborne and surface concentrations of beryllium and beryllium compounds in the workplace.[35] A draft Rule[36] has been proposed and is in review for adoption that would severely reduce acceptable levels of airborne beryllium $\left(0.5 \mu \mathrm{g} / \mathrm{m}^{3}\right.$ as compared with the present OSHA exposure limit of $\left.2 \mu \mathrm{g} / \mathrm{m}^{3}\right)$ and require more extensive personnel and workplace monitoring.

\subsubsection{Fluorine}

Another component of Flibe is fluorine. Fluorine exposure leads to pulmonary edema and skin burns. Inhalation of fluorine gas can cause nose and throat irritation, respiratory tract and lung injury, unconsciousness, and even death. If fluorine makes contact with the skin or eyes, burns may result. These burns are caused by heat produced when fluorine or hydrogen fluoride (the result of fluorine reacting with moisture in the air) reacts with the moisture on the skin. Moreover, fluoride ions can penetrate deeply to the bone, replacing the hydroxide ions in the bone to produce injury.[37]

The IDLH value for fluorine gas is only $39 \mathrm{mg} / \mathrm{m}^{3}$, which could occur at the source of the release. Even assuming that hot fluorine gas quickly forms compounds, such as hydrogen fluoride [by taking hydrogen from humidity in air], there are still risks to workers. HF has a TLV of $2.5 \mathrm{mg} / \mathrm{m}^{3}$ and an IDLH of $24.6 \mathrm{mg} / \mathrm{m}^{3}$.[25]

A significant concern relative to fluorine and the use of Flibe in fusion systems is the potential for the formation and release of HF. When the lithium is fissioned by neutron impact, not only is 
tritium, the radioactive isotope of hydrogen formed, but the loss of the lithium atom leaves a free fluorine atom to combine with available hydrogen. The HF poses a significant corrosion threat, and it has its own set of health risks. One method proposed for control of Flibe $\mathrm{pH}$ is the presence of excess sacrificial beryllium, for example as free flowing pebbles or as fingers or fins over which the flowing Flibe will pass, allowing the HF or free fluoride ions to react back to $\mathrm{BeF}_{2}$.

\subsubsection{Lithium}

Lithium, which in the elemental form is highly pyrophoric, is not of particular concern with Flibe. None of the expected transformations or chemical reactions in the Flibe is expected to produce free lithium.

\subsection{Activation Concerns}

One of the inducements for Flibe in fusion reactors is its inherent ability to produce the fusion fuel tritium from the reaction of fusion neutrons with the lithium in the Flibe. Beryllium will also generate tritium by neutron transmutations.

The HYLIFE-II inertial fusion design concept using Flibe was investigated for activation; the radioisotopes created from neutron activation of pure Flibe are ${ }^{10} \mathrm{Be},{ }^{14} \mathrm{C}$ (assumed released as $\mathrm{CO}_{2}$ gas), and ${ }^{18} \mathrm{~F}$ (assumed released as $\mathrm{F}_{2}$ gas) [38]. The dominant activation product was ${ }^{18} \mathrm{~F}$ [38,39]. Figures 1 and 2 show activation and decay schemes for the main constituents of Flibe. ${ }^{18} \mathrm{~F}$ decays by positron emission and has a 1.8 hour half-life. Other impurity products can also pose activation concerns. There will be some tritium bred in the lithium if ${ }^{6} \mathrm{Li}$ is used to enhance tritium fuel production in the coolant. During a spill, gaseous tritium, in the form of TF or HT, would be released from the Flibe.

Some Flibe impurities are elemental impurities that remain during Flibe mixing, some are intentionally added to the coolant, other impurities intrude into the coolant. Beryllium may contribute oxygen as an impurity. Designers may add an anticorrosive, $\mathrm{MoF}_{6}$ (perhaps at 10 ppm by weight). Secondary coolant $\left(\mathrm{NaBF}_{4}\right.$ was the secondary in the HYLIFE-II design) leakage through the heat exchangers might intrude into the Flibe. Either of these additions mean that there will be impurities that can be activated. Also, Flibe can attack Mn in stainless steel, so erosion products from wall materials are possible, depending on the designer's choice of material. Tobin [38] listed the radioisotopes generated from impure Flibe that initially contained 10 ppm by weight of oxygen and some other impurities:

$\begin{array}{lll}{ }^{46} \mathrm{Sc} & { }^{59} \mathrm{Fe} & { }^{60} \mathrm{Co} \\ { }^{54} \mathrm{Mn} & { }^{57} \mathrm{Co} & { }^{55} \mathrm{Zn} \\ { }^{56} \mathrm{Mn} & { }^{58} \mathrm{Co} & \end{array}$




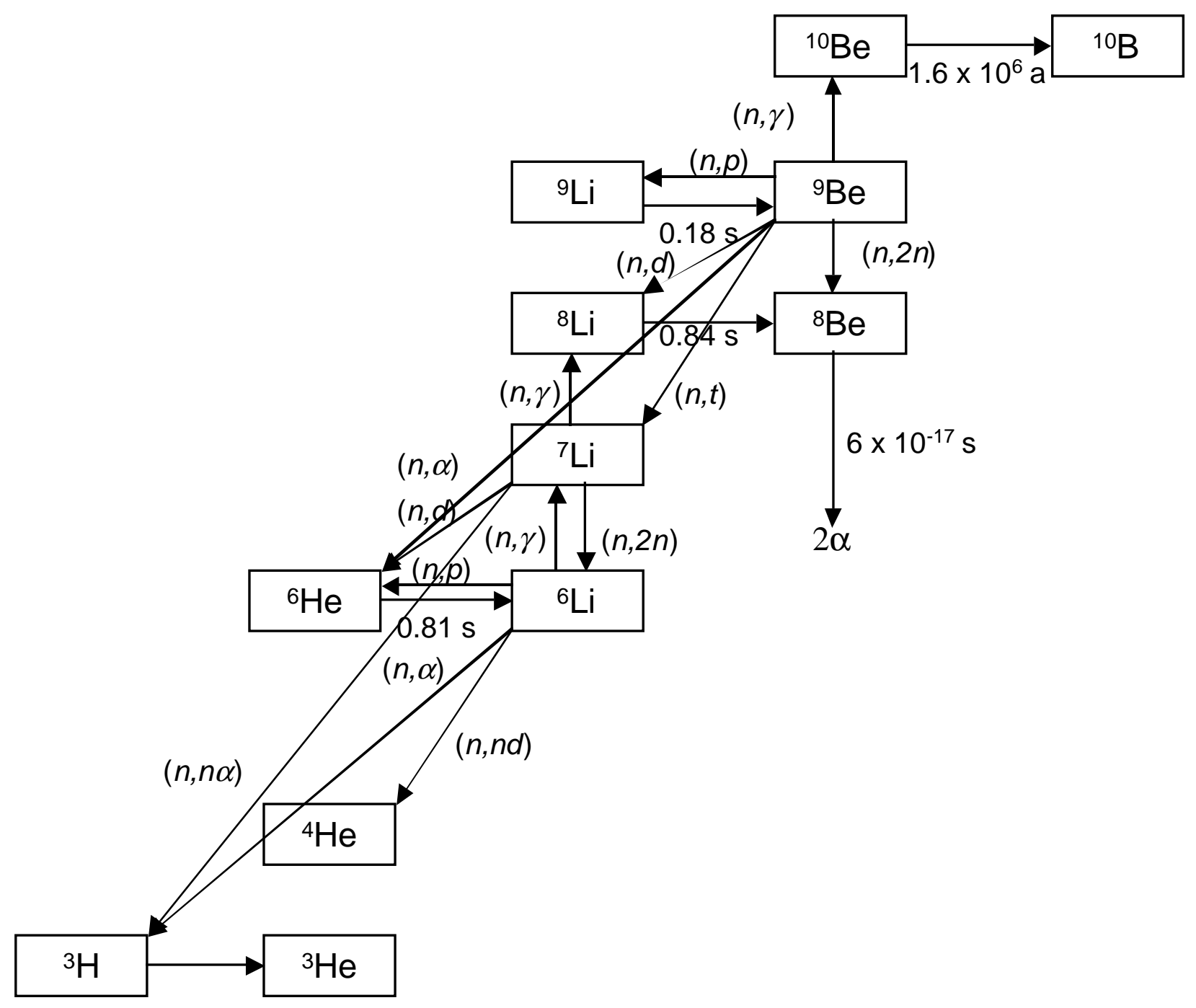

Figure 1. Activation and decay paths for lithium and beryllium in Flibe.[40] 


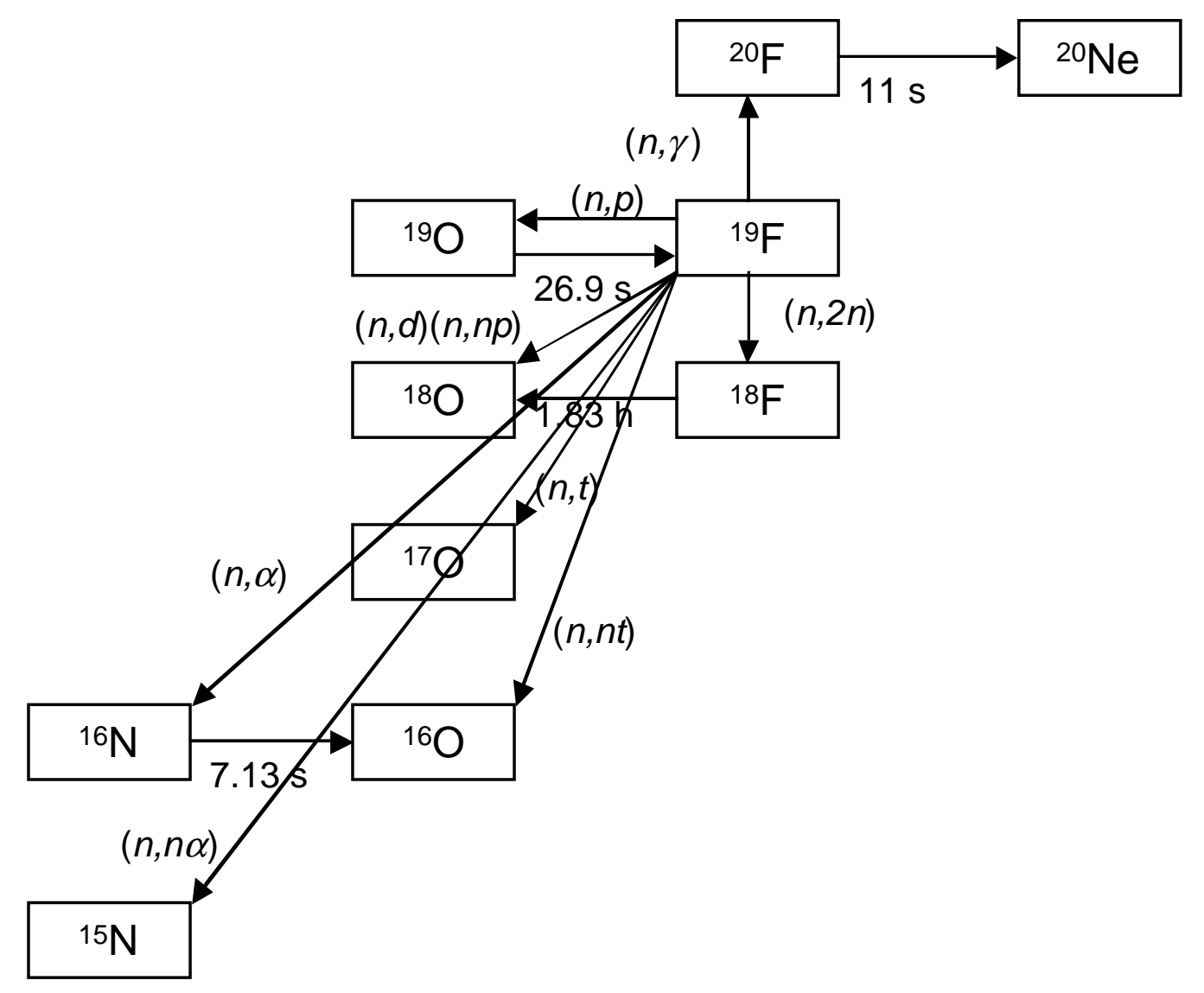

Figure 2. Activation and decay processes for fluorine in Flibe and oxygen impurity.[40]

Considering that stainless steel 316 with a Mn component (rather than nickel) might be present, erodants could be generated and activated [38], giving the following radioisotopes:
${ }^{54} \mathrm{Mn}$
${ }^{55} \mathrm{Fe}$
${ }^{58} \mathrm{Co}$
${ }^{56} \mathrm{Mn}$
${ }^{59} \mathrm{Fe}$
${ }^{60} \mathrm{Co}$

Some of these radioisotopes may oxidize in air, but concentrations should be low since the impurity concentrations were in the ppm range. The actual curie inventory of these radioisotopes depends on fluence and the level of impurity or erosion. For HYLIFE-II, Tobin [38] showed site boundary doses between 1 and 26 rem for each of the impurity and erodant radioisotopes listed above. The ${ }^{18} \mathrm{~F}$ from pure Flibe gave a site boundary dose of 340 rem for HYLIFE-II. Considering that workers would be closer to the more concentrated source of these radioisotopes, their doses would be higher than the values stated for the site boundary unless appropriate mitigative actions are taken. Specific calculations need to be performed for the magnetic fusion designs under consideration to determine the worker and the site boundary doses. While these calculations are important, it is also noted that the MSRE operated successfully from 1965 to 1969 without any extreme personnel safety events (i.e., no radiation exposure over 15 rem, and 
no fatalities or life-threatening injuries).[16,41] A review of experience by MSRE maintenance personnel indicated that handling the molten salt was not difficult [42] and that the maximum exposure any maintenance personnel received was $<0.5$ rem per year.[43] Most of that exposure came from dealing with systems containing fission fuel salt and fission products rather than coolant salt.

One of the important concerns regarding tritium produced in Flibe is its propagation to other parts of a fusion system. Solubility of hydrogen isotopes in Flibe is very low. That means that even a small concentration of tritium produced in the Flibe by neutron transmutations will have a very high chemical potential and will readily exit the Flibe by whatever means are available. A particular concern in this regard is its ability to pass through the walls of heat exchanger tubes or other structures and enter the atmosphere or a secondary coolant stream. Transport of tritium in Flibe flowing in heat transfer systems is largely by convection. Therefore, the same design configurations that will be used to maximize heat transfer from the Flibe will also maximize the transport of tritium.[44]

In a related matter, a number of experiments are being considered for exploring tritium safety issues in Flibe. Many of these are concerned with the mobilization of tritium from Flibe.[45,46] It is not clear whether there are reasonable means for getting tritium into Flibe for such experiments other than actual neutron irradiation. This is because of the complex chemistry of the various reactions involving the fluorine, beryllium, lithium, and the tritium produced. One priority in the forthcoming research should be to develop a successful tritiating procedure for Flibe.

\subsection{Operational Concerns}

Whether using Flibe in a laboratory situation to conduct experiments, or in an operating fusion facility, there are concerns for health and safety of workers, the public, and the environment that arise from working with the material. In this section we address some of these issues and make recommendations for dealing with them.

Workers at fusion experiments are to be protected from routine hazards to a level commensurate with that of typical industrial environments.[47] Therefore, because molten salts are an exotic coolant, Flibe must be assessed for personnel safety issues. Appendix A shows an initial framework for listing personnel exposure to hazardous agents in the workplace.[48] Assessing Flibe with this framework shows several hazardous agent categories where Flibe may be more hazardous than a typical industrial environment using hot water and steam, which is the typical coolant at a steam electric power plant and at many fusion experiments. These hazardous agent categories from Appendix A are thermal energy, radiation energy, and chemical energy.

The inherent chemical and activation issues with Flibe and its components were discussed above. There are two chemical exposure scenarios with Flibe. These are maintenance contact and operational exposure from spills during plant operation. Maintenance-related accidents can be 
on the order of 30 to $38 \%$ of worker accidents in a chemical facility.[49] While nuclear facilities could have lower percentages of worker accidents during maintenance due to rigorous work planning, detailed procedures and compliance with regulations, worker exposure to solidified Flibe during cooling system maintenance remains a possibility. Tasks such as pump and valve seal maintenance or replacement, yearly instrument recalibration, etc., could lead to skin contact with the salt. Fortunately, maintenance exposure should be infrequent and deal with small masses of Flibe.

With respect to thermal energy, the Flibe is used at temperatures higher than typical steam temperatures of 260 to $315^{\circ} \mathrm{C}$, although high temperature, high pressure steam can fatally scald a worker. Operating near or above $540^{\circ} \mathrm{C}$ means that workers would be exposed to a high heat stress environment near the cooling system equipment (piping, heat exchangers, pumps, etc.). The environment would be more severe than for a steam plant, where working fluid temperatures are about half as high. Engineering controls to reduce the hazard that this high temperature environment imposes might be piping insulation or double walled piping, high air flow general ventilation, and physical separation, such as the use of pipe corridor exclusion areas. Administrative controls might include exclusion areas to preclude admission near the cooling system, limiting stay times for workers in the coolant system areas while the system is hot (the Flibe does not melt until over $455^{\circ} \mathrm{C}$, so even with solid Flibe there can be a considerable heat load), and using a heat-alert program [34] to protect workers. Personal protective equipment in the form of water-cooled garments, similar to the protective clothing worn for furnace maintenance work, could be considered if personnel are required to stay in the area.

Excluding workers from locations near the coolant piping would be a prudent precaution if there is any concern about a Flibe leak or spill. Modest protective clothing will not protect workers from a hot Flibe spill, only robust, specially designed thermal suits will offer protection. Second degree burns can occur when the skin is elevated to $71^{\circ} \mathrm{C}$ for only 60 seconds. Higher temperatures reduce the time to damage, such as $100^{\circ} \mathrm{C}$ for 15 seconds results in second degree burns. A tolerance limit for skin exposure to heat is suggested to be $0.25 \mathrm{Watt} / \mathrm{cm}^{2}$.[50] The recommended approach to protect the workers from a hot Flibe spill is separation through exclusion areas.

Maintenance should only be conducted on the cooling system when the Flibe has cooled enough to make physical contact without concern for burns. Maintenance guidance [51] suggests that maintenance be carried out in temperature ranges less than $54^{\circ} \mathrm{C}$ for relative humidity over $20 \%$. If that guidance is unacceptable, then remote maintenance must be considered in the system design.

An important issue to note is that a spill of hot molten salt in a room with air could lead to a fire of substances that contact, or remain in proximity to, the salt. While Flibe itself is not flammable in air [15], the non-stoichiometric mixture produced during neutron irradiation may be reactive wityh air, moist aire, or steam. No experimental data exist on the mobilization of tritium and other activated materials from neutron-irradiated Flibe under air or steam exposure. Given the 
radiological hazard of tritium, ${ }^{18} \mathrm{~F}$, and other activation products and the chemical toxicity of beryllium, experiments are needed to better define the radiological safety hazard under accident conditions. Furthermore, the high temperature conduction or radiation heating from the $455^{\circ} \mathrm{C}$ temperature range could ignite some grease or oil lubricants (ignition typically in the 260 to $370^{\circ} \mathrm{C}$ range), many types of paint (ignition typically in the 245 to $455^{\circ} \mathrm{C}$ range), some types of electrical wiring insulation (typically, 425 to $590^{\circ} \mathrm{C}$ surface temperature range) [52], and other combustible materials. The Flibe temperature could also decompose concrete, so providing an insulation barrier, such as metal liners, in the design should be examined. Fire poses a worker safety concern by inhalation of hot combustion products, exposure to carbon monoxide, carbon dioxide and other toxic gases, and exposure to heat.

Fortunately, maintenance exposure should be infrequent. Engineering controls to preclude skin contact with Flibe would be to select or design instruments that can be calibrated without opening to the process fluid, choose long life seals, and design for maintainability. Administrative controls might be to limit maintenance activity by using reliability centered maintenance approaches rather than periodic preventive maintenance, and to use mockups of equipment to be maintained or practice on the facility before it becomes activated-these efforts would support maintenance planning and allow workers to have practice sessions. Personal protective equipment might include gloves and protective clothing to serve as a barrier to the Flibe. Such equipment would also be required to serve as contamination control protective clothing. It should be noted that beryllium in solid and powder form is safely handled at manufacturing companies such as Brush-Wellman in Ohio.

A Flibe spill during facility operation could result in tritium, beryllium compound, and activated corrosion product release. This scenario is likely to be more hazardous than maintenance due to the possibility for large mass releases that could reach Immediately Dangerous to Life or Health (IDLH) concentrations. An assumption made in the radiological calculations discussed above was that the fluorine was released as $\mathrm{F}_{2}$ gas. As stated earlier, the actual release form must be determined. However, fluorine has been reasonably safely handled at uranium gaseous diffusion plants for many years.

Calculations by Dolan and Longhurst [39] showed that if one kilogram of Flibe was assumed to be released as aerosol during a large spill event, then 660 grams of $\mathrm{LiF}$ and 340 grams of $\mathrm{BeF}_{2}$ would be released. Using standard dispersion assumptions, the Be compound concentration in the building would be high enough to require worker protection. The LiF compound may also pose debilitating health effects [32], but currently only lithium hydride has been studied for its health concerns from workplace exposures. Worker protection could be in the form of timely evacuation or use of supplied air protective suits to prevent radiological contamination, inhalation of beryllium compound and other particles, and fluorine gas from contacting the skin. 


\section{CONCLUSIONS}

This preliminary investigation of the personnel safety aspects of Flibe molten salt identified three hazard areas where the salt could present safety challenges beyond the typical industrial environment. These three areas are thermal energy in the coolant (high temperature but low pressure), radioactivity of the coolant and its impurities, and chemical toxicity of the coolant and its impurities. In each case, several initial suggestions to enhance personnel safety through design, operational approach, and use of protective equipment were presented. Qualitatively, the molten salt hazards appear to be manageable, since similar hazards have been, or are currently being, managed in other industries. Harvesting the good practices formed from operating experience at such facilities would support personnel safety enhancement through design rather than relying on administrative procedures or personal protective equipment.

Based on this assessment, the following areas require further research:

1. Mobilization of radiologically hazardous (e.g., $\mathrm{T},{ }^{18} \mathrm{~F}$ ) and chemically toxic materials (e.g., beryllium) from neutron-irradiated Flibe, including impurities, during air or steam interaction

2. Characterization of the physical (e.g., aerosol, vapor), chemical, and radiological form of the mobilized materials.

3. Tritium mobilization and transfer to structures surrounding a Flibe system to evaluate the extent to which such tritium may be a hazard

4. Health effects of LiF

5. The need for additional design provisions (e.g., double containment) or protective measures (e.g., special clothing) in light of the stricter limits on occupational exposure to beryllium. 


\section{REFERENCES}

1. X. M. Chen et al., "Fitted Equation of State for Flibe Gas," Fusion Technology, 26 (1994) pp. 912-916.

2. A. P. Malinauskas and D. M. Richardson, "The Solubilities of Hydrogen, Deuterium, and Helium in Molten $\mathrm{LiF}-\mathrm{BeF}_{2}$," Industrial and Engineering Chemistry Fundamentals, 13 (1974) p. 242.

3. B. C. Blanke et al., "Density and Viscosity of Fused Mixtures of Lithium, Beryllium, and Uranium Fluorides," MLM-1086 (March 1959).

4. T. Terai et al., "Compatibility of structural materials with $\mathrm{Li}_{2} \mathrm{BeF}_{4}$ molten salt breeder," Journal of Nuclear Materials, 258-263 (1998) pp. 513-518.

5. J. R. Keiser et al., "Compatibility of Molten Salts with Type 316 Stainless Steel and Lithium," Journal of Muclear Materials, 85-86 (1979) pp. 295-298.

6. P. E. Field and J. H. Shaffer, "The Solubilities of Hydrogen Fluoride and Deuterium Fluoride in Molten Flourides," Journal of Physical Chemistry, 71 (1967) pp. 3218-3222.

7 . K. Yajima et al., "Surface Tension of Lithium Fluoride and Beryllium Fluoride Binary Melt," Journal of Physical Chemistry, 86 (1982) pp. 4193-4196.

8. G. D. Robbins and J. Braunstein, "Electrical Conductivities and Ionic Mobilities in the Molten LiF-BeF 2 System,” ORNL-4548 (February 1970) pp. 156-159.

9. S. Cantor et al., "Physical Properties of Molten-Salt Reactor Fuel, Coolant, and Flush Salts," ORNL-TM-2316 (August 1968).

10 . V. A. Maroni et al., "Some Preliminary Considerations of a Molten Salt Extraction Process to Remove Tritium from Liquid Lithium Fusion Reactor Blankets," Nuclear Technology, 25 (1975) pp. 51-56.

11. S. Cantor et al., "Vapor Pressures of Fluoride Melts," ORNL-4076 (December 1966) pp. $24-25$.

12. C. E. Bamberger, Advances in Molten Salt Chemistry, Vol. 3, Plenum, New York (1975) p. 177.

13 . E. M. Larsen and L. J. Wittenberg, "The Chemistry of Molten $\mathrm{Li}_{2} \mathrm{BeF}_{4}$," Fusion Technology, 10 (1986) pp. 990-994.

14 . J. H. Shaffer, "Solubility of HF in LiF-BeF Mixtures," ORNL-2626 (October 1958) pp. 85-86. 
15 . R. W. Moir, “HYLIFE-II Inertial Confinement Fusion Reactor Design,” Fusion Technology, 19 (May 1991) pp. 617-624.

16 . P. N. Haubenrich and J. R. Engel, "Experience with the Molten-Salt Reactor Experiment," Nuclear Applications \& Technology, 8 (February 1970) pages 118-136.

17 . R. W. Moir et al., "HYLIFE-II: A molten-salt inertial fusion energy power plant designFinal Report," Fusion Technology, 25 (1994) 5-25.

18. H. Moriyama et al., "Molten salts in fusion nuclear technology," Fusion Engineering and design, 39-40 (1998) pp. 627-637.

19. A. Suzuki et al., "Change of tritium species in $\mathrm{Li}_{2} \mathrm{BeF}_{4}$ molten salt breeder under neutron irradiation at elevated temperature," Journal of Nuclear Materails, 259-263 (1998) pp. 519524.

20 . A. Suzuki et al., "Mechanism on Change of Tritium species in $\mathrm{Li}_{2} \mathrm{BeF}_{4}$ Molten Salt Breeder under Neutron Irradiation at Elevated Temperature," Fusion Technology, 34 (Nov 1988) pp.526-530.

21. H. Tas et al., "Liquid Breeder Materials," Journal of Nuclear Materials, 155-157 (1988) pp. 178-187.

22. C. L. Greenstock and N. E. Gentner, A Review of Potential Health Hazards Associated with Occupational Exposure to Beryllium and its Compounds, CFFTP G-9031, Ontario Hydro, Canada (April 1990).

23. Health Assessment Document for Beryllium, Final Report, PB88-179205, U.S. Environmental Protection Agency, Washington, D.C. (November 1987).

24. Syracuse Research Corporation, Toxicological Profile for Beryllium, ATSDR/TP-88/07, Agency for Toxic Substances and Disease Registry (ATSDR), U.S. Public Health Service in collaboration with U.S. Environmental Protection Agency (EPA) (December 1988).

25. NIOSH Pocket Guide to Chemical Hazards, National Institute for Occupational Safety and Health, Department of Health and Human Services publication 97-140 (June 1997).

26. B. Mason, Principles of Geochemistry, $3^{\text {rd }}$ Ed., John Wyley \& Sons, Inc., New York (1966).

27 . H. J. M. Bowen, Environmental Chemistry of the Elements, Academic Press, New York (1979).

28 . C. D. Klaassen, editor, Casarett and Doull's Toxicology, the basic science of poisons, fifth edition, McGraw-Hill, New York (1996) ch. 23.

29 . A. G. Harmsen et al., "Health Risk Implications of Using Beryllium in Fusion Reactors," Journal of Nuclear Materials, 122 \& 123 (1984) pp. 821-826. 
30 . 1998 TLVs and BEIs, Threshold Limit Values for Chemical Substances and Physical Agents, Biological Exposure Indices, American Conference of Governmental Industrial Hygienists, Cincinnati, OH, ISBN 1-882417-23-2 (1998).

31. Code of Federal Regulations, Title 29, Labor, Part 1910, Occupational Safety and Health Standards, section 1000, Air Contaminants (July 1, 1998).

32. G. D. Clayton and F. E. Clayton, editors, Patty's Industrial Hygiene and Toxicology, fourth edition, volume II, part C, John Wiley \& Sons, New York (1994), pages 2087-2093.

33 . H. H. Sterner and M. Eisenbud, "Epidemiology of Beryllium Intoxication," Archives of Industrial Hygiene and Occupational Medicine, 4 (1951) pp. 123-157.

34 . B. A. Plog et al., editors, Fundamentals of Industrial Hygiene, third edition, National Safety Council, Itasca, IL (1988) chs. 7, 12.

35. DOE G 440.1-7, Interim Chronic Beryllium Disease Prevention Program, U.S. Department of Energy (July, 1997).

36 . "Department of Energy 10 CFR Part 850, Chronic Beryllium Disease Prevention Program," Federal Register, 63, No. 232 (December 3, 1998), pp. 66940-66975.

37. Lawrence Livermore National Laboratory, Health \& Safety Manual, Supplement 21.12, "Safe Handling of Fluorine," (April 1990).

38 . M. T. Tobin, "Neutronics Analysis for HYLIFE-II," Fusion Technology, 19 (May 1991) pp. 763-769.

39 . T. J. Dolan and G. R. Longhurst, Safety and Environmental Issues of HYLIFE-II, EGG-FSP8653, Idaho National Engineering Laboratory (October 1989).

40 . F. W. Walker et al., eds., Nuclides and Isotopes, $14^{\text {th }}$ Ed., General Electric Company, San Jose, CA (1989).

41. Operational Accidents and Radiation Exposure Experience Within the United States Atomic Energy Commission, 1943-1975, WASH-1192, USAEC Division of Operational Safety (1975).

42 . P. N. Haubenrich and J. R. Engel, "Recent Experience with the Molten-Salt Reactor Experiment," Transactions of the American Nuclear Society, 11 (1968) page 619.

43 . P. N. Haubenreich, "Maintenance of the Molten Salt Reactor Experiment," Transactions of the American Nuclear Society, 13 (1970) Winter Meeting, pp. 789-790.

44 . G. R. Longhurst and T. J. Dolan, HYLIFE-II Tritium Management System, EGG-FSP-9971 (1993). 
45. Y. Asaoka et al., "Equilibrium Distributions of Tritium in Liquid Lithium/Molten Salt Systems," Journal of Nuclear Materials, 179-181 (1991) pp. 879-881.

46 . J. Oishi et al., "Tritium Recovery from Molten LiF-BeF 2 Salt," Fusion Engineering and Design, 8 (1989) pp. 317-321.

47 . Safety of Magnetic Fusion Facilities: Requirements, DOE-STD-6002-96, US Department of Energy (May 1996) section 3.2.

48 . L. C. Cadwallader, Suggestions for a Personnel Safety Master Logic Diagram, ITER/US/98/EN/SA-04, INEEL Fusion Safety Program (June 9, 1998).

49. A. R. Hale et al., "Evaluating Safety in the Management of Maintenance Activities in the Chemical Process Industry," Safety Science, 28 (1998) pp. 21-44.

50 . A. E. Cote and J. L. Linville, Fire Protection Handbook, $17^{\text {th }}$ Ed., National Fire Protection Association, Quincy, MA (1992) sec. 3, ch. 1.

51 . J. P. Bongarra et al., Human Factors Design Guidelines for Maintainability of Department of Energy Nuclear Facilities, UCRL-15673, Lawrence Livermore National Laboratory (June 1985) sec. 3.2.4.5.

52 . L. S. Cole, Investigation of Motor Vehicle Fires, Lee Books, Novato, CA (1992). 
APPENDIX A

PRELIMINARY PERSONNEL SAFETY MASTER LOGIC DIAGRAM

Level 1

Personnel

Hazard

Level 2

Personnel

Exposure

Level 4

Event

Conditions

Level 5

Failure

Events

Leading

to Injury

Level 3
Barriers
Acute or Chronic

Personnel Injury

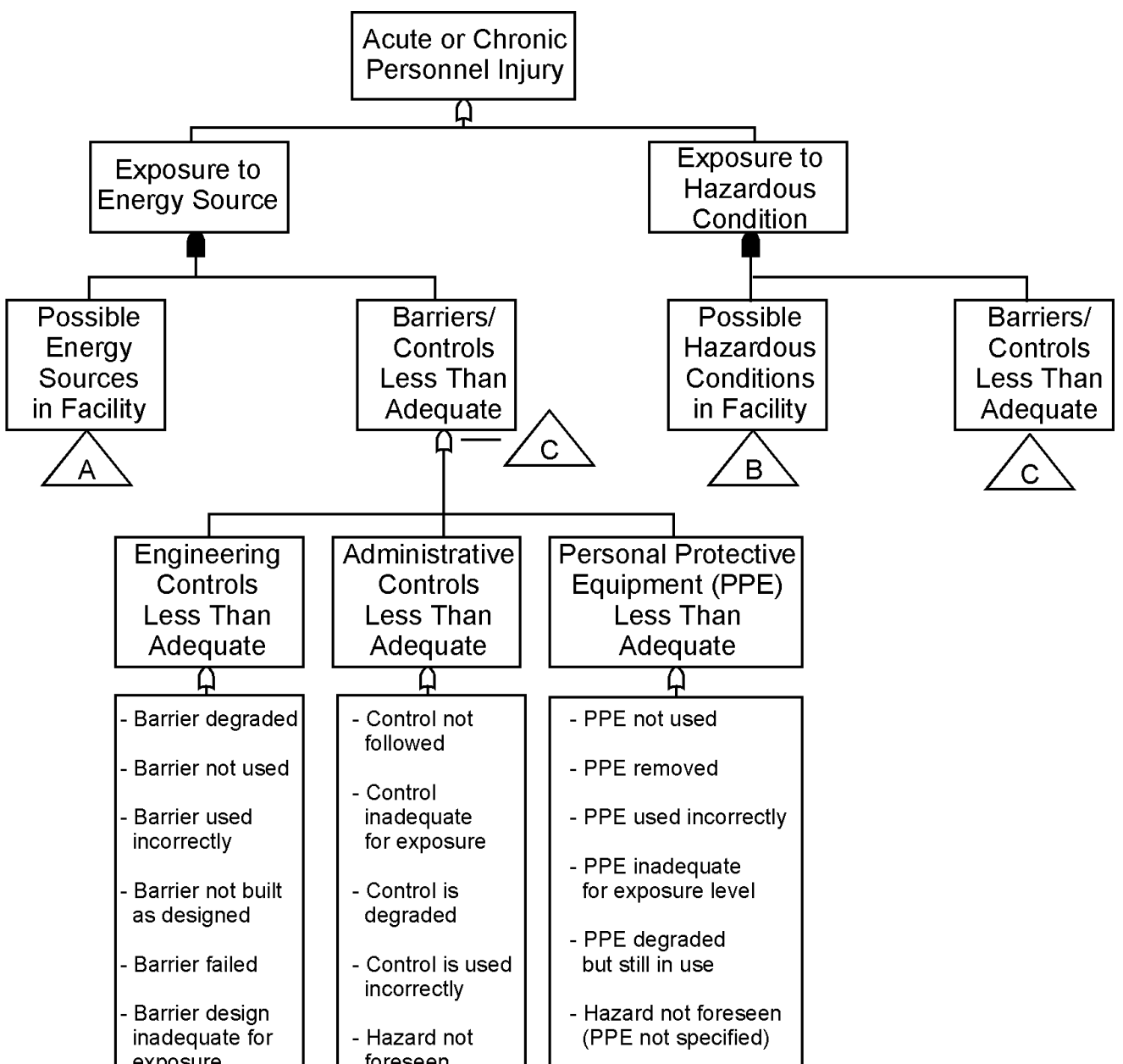

exposure

- Hazard not

foreseen (control

not specified)

- Monitoring

ineffective

for hazard

- Monitoring not

used correctly

- Monitoring

degraded

- Monitoring was

not required

(hazard not

foreseen)

Monitoring fails

to sense or

annunciate

foreseen

(control not

specified)

Personal Protective

uipment (PPE)

Less Than

Adequate

- PPE not used

-PPE removed

PPE inadequate

- PPE degraded

(PPE not specified)

C98 04121 


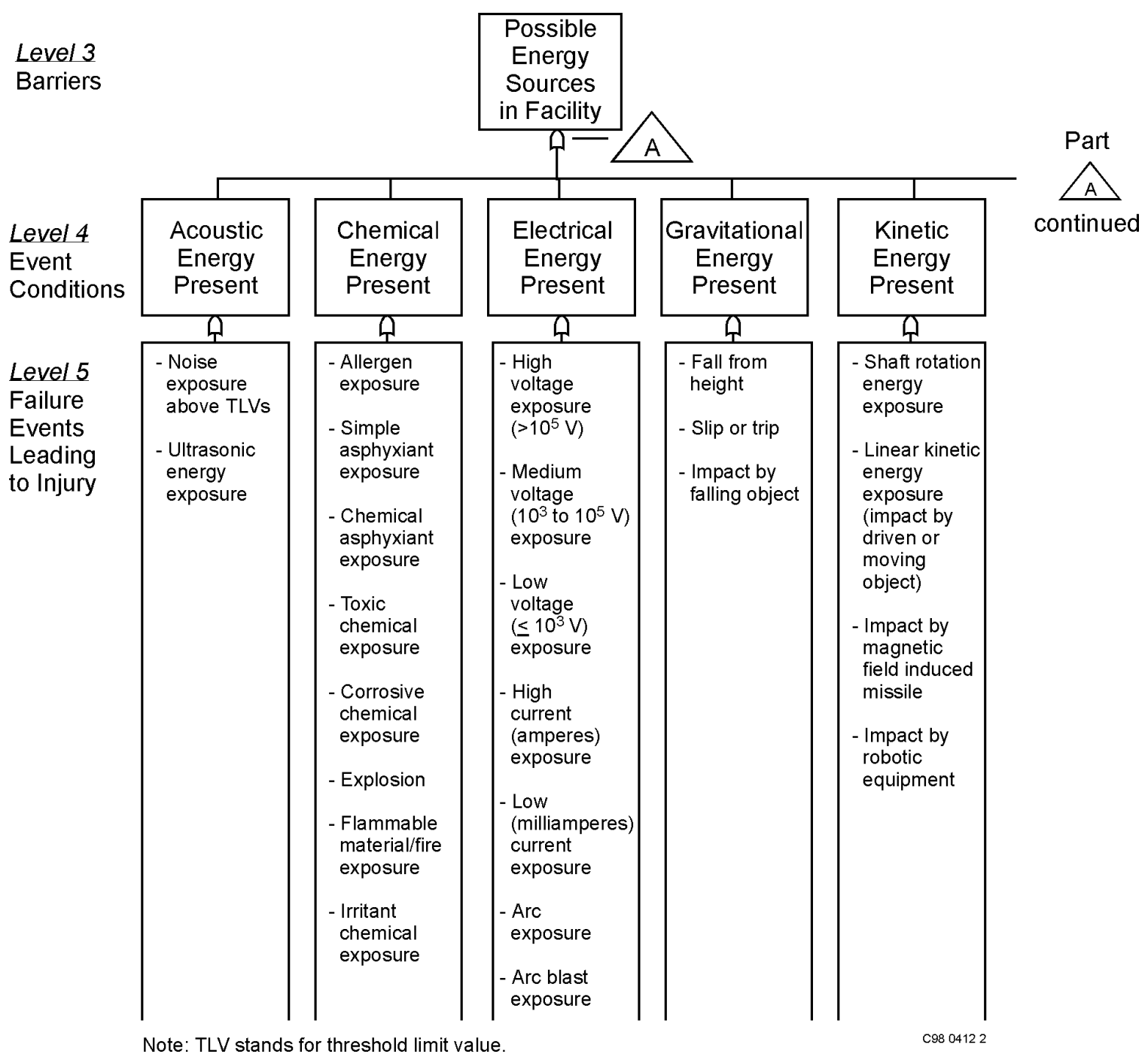




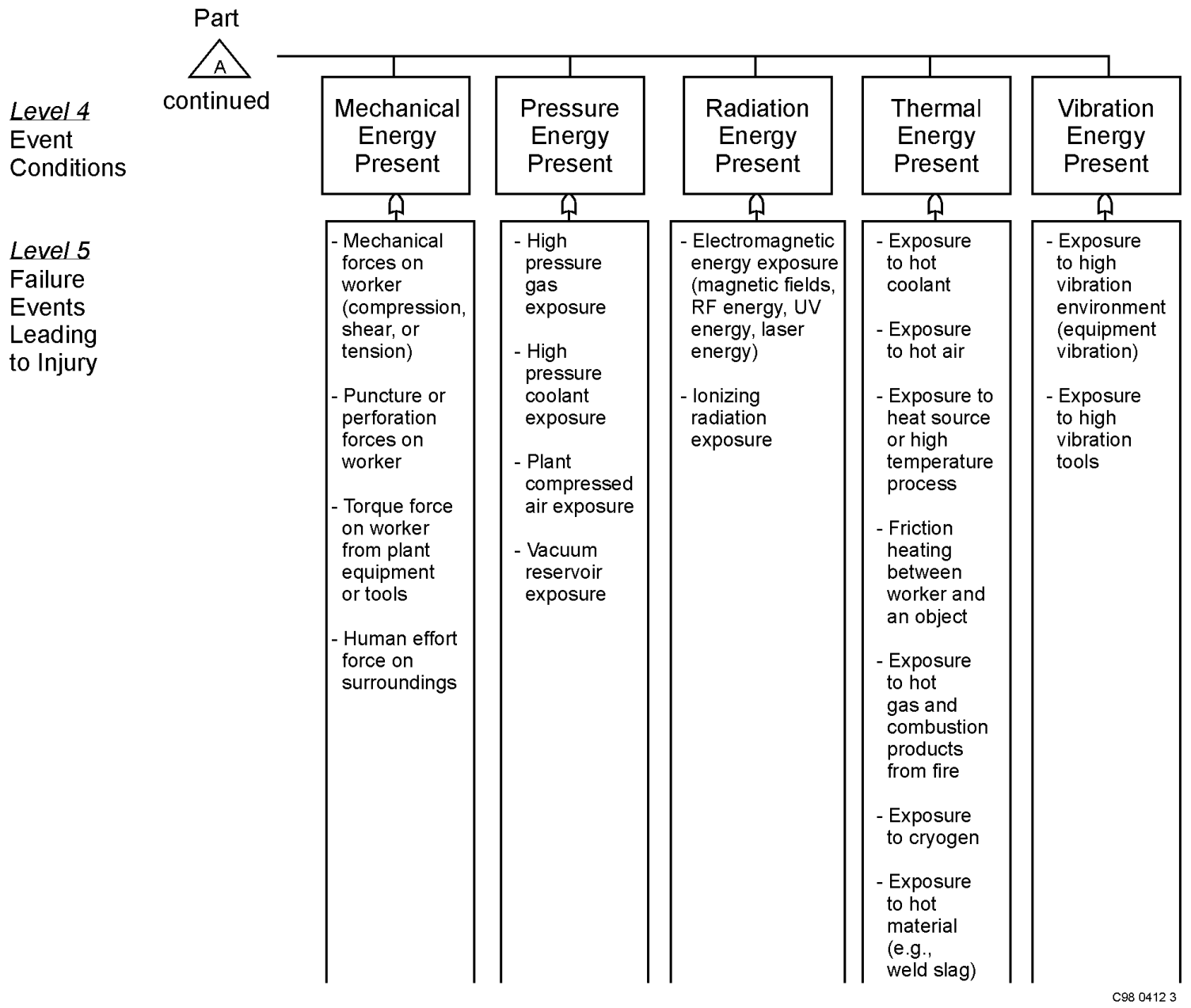


Level 3

Barriers

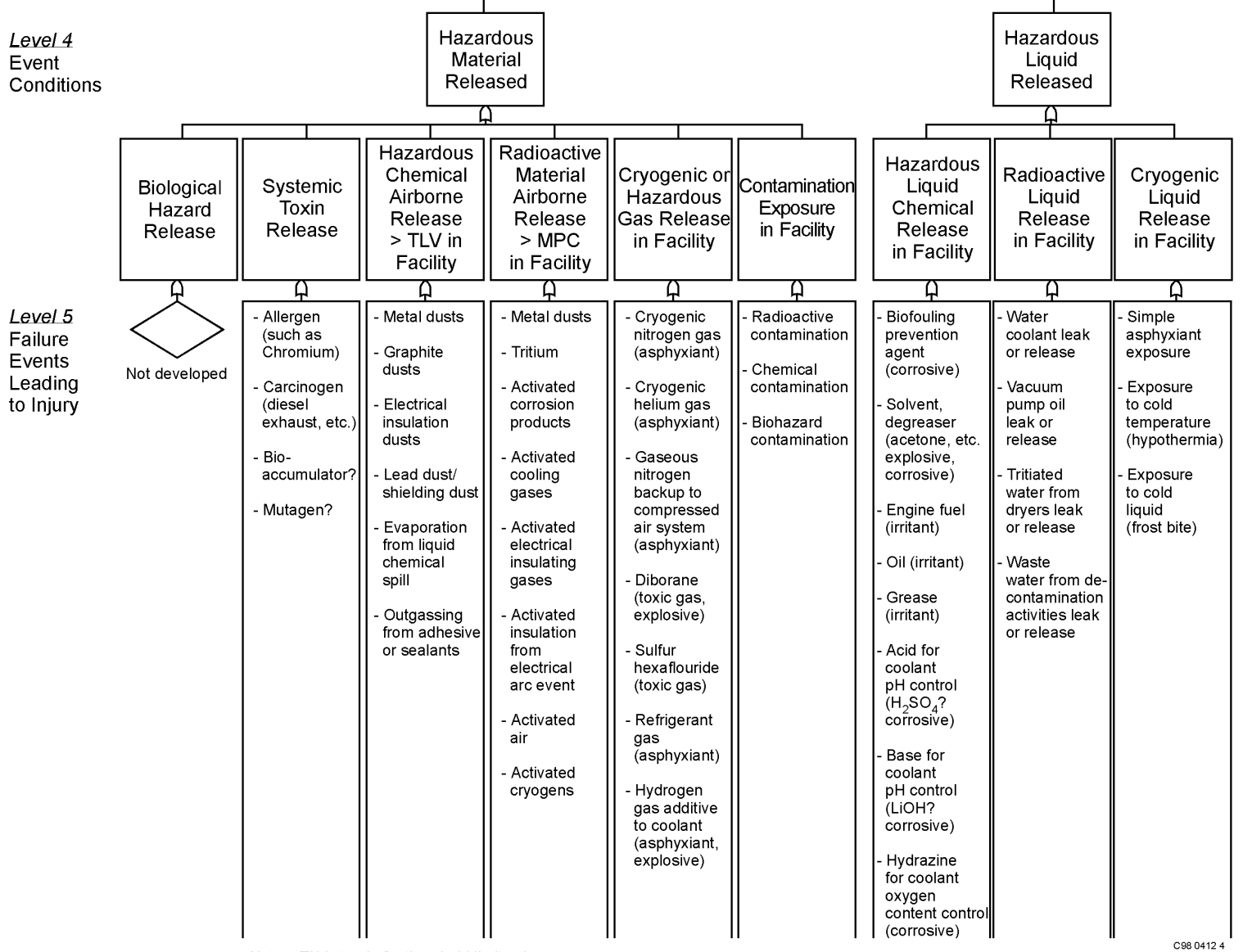

Notes: TLV stands for threshold limit value.

MPC stands for maximum permissible concentration. 